\title{
Genetic Characteristics of Brown Trout Salmo trutta from the Tatra National Park in Poland
}

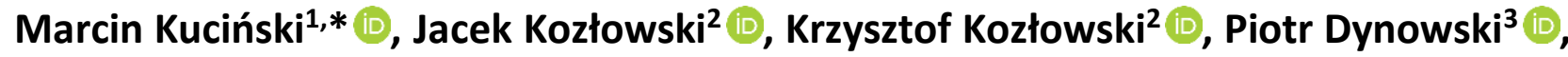 \\ Dorota Fopp-Bayat $^{2}$ (D) Konrad Ocalewicz $^{1}$ (D)
}

\author{
${ }^{1}$ University of Gdansk, Institute of Oceanography, Department of Marine Biology and Ecology, 81-378 Gdynia, Al. M. \\ Piłsudskiego 46, Poland. \\ 2University of Warmia and Mazury in Olsztyn, Department of Ichthyology and Aquaculture, Oczapowskiego 5, 10-719 \\ Olsztyn, Poland. \\ ${ }^{3}$ University of Warmia and Mazury in Olsztyn, Department of Botany and Nature Protection, 10-719 Olsztyn, Poland.
}

\section{How to cite}

Kuciński, M., Kozłowski, J., Kozłowski, K., Dynowski, P., Fopp-Bayat, D., Ocalewicz, K. (2021). Genetic Characteristics of Brown Trout Salmo trutta from the Tatra National Park in Poland. Turkish Journal of Fisheries and Aquatic Sciences, 21, 479-490. http://doi.org/10.4194/1303-2712-v21_10_01

\section{Article History \\ Received 11 August 2020 \\ Accepted 01 June 2021}

First Online 04 June 2021

\section{Corresponding Author}

Tel.: +48798537506

E-mail: marcin_kucinski1@o2.pl

\section{Keywords}

Conservation genetics

Genetic diversity

Genetic structure

Microsatellite and mitochondrial DNA

Salmo trutta

\begin{abstract}
In the present study the genetic diversity and structure of the brown trout in the Tatra National Park (TNP) was analyzed by application of ten microsatellites and one mitochondrial DNA markers. For this purpose, a total of 96 fish from 7 main streams located on the territory of the TNP were sampled. Examined fish was characterized by a moderate level of the genetic diversity $(I=1.196-1.549)$ and $P I C=0.567-0.707)$. The mean values of observed $\left(H_{0}\right)$ and expected heterozygosity $\left(H_{e}\right)$ varied from 0,577 to 0,760 and from 0,609 to 0,723 , respectively. Based on genetic analysis, five haplotypes were identified, and the computed haplotype diversity $(h)$ and nucleotide diversity $(\pi)$ values were 0.561 and 0.001 , respectively. Assessed genetic differentiation between the examined groups varied from 0.016 do 0.085 and the global test of differentiation (Fst $=0.062$ ) among groups provided statistically insignificant values. Constructed Bayesian skyline plot revealed stable population size, however an evidence of a historical decline of the population size in the studied fish was detected. Similarly, to microsatellite DNA analysis, the obtained data on mtDNA analysis showed weak genetic clustering, where two genetic clusters were identified, however, haplotype frequencies did not follow geographical pattern.
\end{abstract}

\section{Introduction}

The Tatra National Park (TNP) in Poland is an Alpine character national park located in the Southern Poland, covering a territory of about $212 \mathrm{~km}^{2}$. Within the park several streams and over 30 mountain lakes are present. Due to the unique wildlife character and rich landscape, the park has been listed as UNESCO biosphere reserves and IUCN national park of category II. TNP has been also included in the European network of nature protection areas Natura 2000 (IUCN, 2021a; UNESCO, 2021). Moreover, the park is a natural habitat of many endangered animal species including fish, such as: brown trout (Salmo trutta), European grayling (Thymallus thymallus), Eurasian minnow (Phoxinus phoxinus) and Alpine bullhead (Cottus poecilopus). All listed fish species are strictly protected within the TNP territory by means of banning angling activity and carrying out the fishery supplementation by hatchery stocking material (Glowacinski \& MakomaskaJuchiewicz, 1992; Witkowski et al., 2008; Galas \& Tonczyk, 2020).

The brown trout that constitutes an essential part of the ichthyofauna in TNP is a very interesting salmonid species in terms of ecology and biology. The species is a member of Salmonidae family that is native to the coldtemperate climate regions of the Northern Hemisphere. Salmonids are predators feeding on small crustaceans, aquatic insects or other fish. Many representatives of this family characterize by anadromous lifestyle, 
displaying semelparity or iteroparity. Frequently, they take large-scale migration, coming back to its birthplace in an upper part of rivers or streams. Most of salmonids lay eggs in excavated redds of gravel stream bed (Kottelat \& Freyhof, 2007; FishBase 2021). Brown trout shows great morphological, behavioral, and genetic diversity and numerous ecological morphs and phylogenetic lineages of this species were distinguished. The species comprises migratory and stationary freshwater forms that inhabit marine estuaries, streams, ponds, rivers and lakes across Europe and Asia (Turan et al., 2009). Brown trout is iteroparous species, which takes maturity in 3-4 years and spawns usually during November-December. Females select spawning sites in rivers and streams with swift current. Males guard and defend females against other males. The species prefers cold, and well-oxygenated upland waters with adequate cover in form of submerged rocks, undercut banks and overhanging vegetation. The sea forms forage mainly close to coast, not very far from estuary of natal river. In turns, the resident forms of species spend entire life in freshwater, spawning usually in smaller tributaries of inhabited streams. Juveniles mainly forage on aquatic and terrestrial insects, adults on mollusks, crustaceans, and small fish. Brown trout is territorial, protecting the established territories (Kottelat \& Freyhof, 2007; FishBase, 2021).

Brown trout is also economically valuable fish and subject of both commercial and recreational fisheries (FishBase, 2021). During last few decades, the distribution range and the population size of the brown trout has significantly declined through habitat changes, overfishing, poaching, inter- and intraspecies hybridization and pollution of the natural environment (IUCN, 2015b). To protect the local populations of brown trout, the extensive conservation management strategies based mainly on the stocking actions have been developed. Unfortunately, during the last three decades domesticated strains of non-native brown trout have been released to many European river systems without consideration of the genetic structure of the native populations (Kohout et al., 2012). As a result, many of the held fishery supplementation actions, both for the recreational and the commercial purposes, resulted in irreversible disappearance of many indigenous populations of the brown trout. In Poland, wide-scale stocking activities of salmonids has begun from the beginning of twenth century and enabled to conserve the species in Polish water (Dębowski, 2018). Despite brown trout is considered as the least concern species (LC) its existence in many regions, including TNP is actively protected by stocking activities and restriction in fishery and angling activities (IUCN, $2021 a, b$ ).

To date, phylogeography and population genetic structure of this species have been broadly investigated across Europe, where five main evolutionary lineages has been distinguished, namely: (1) Atlantic, (2) Danubian, (3) Mediterranean, (4) Adriatic and (5) Marble. All identified lineages represent geographically separate clusters, with exception to the latter three that overlap within Mediterranean basin (Bernatchez, 2001). Numerous detailed genetic studies revealed deeper genetic structure within identified main lineages, e.g., Duero, Tigris and Balkan clusters (Suarez et al., 2001; Bardakci et al., 2006; Maric et al., 2006). In Central Europe, many genetic studies has been performed on wild and hatchery stocks to evaluate the long-time effects of stocking activities as well as to delineate the sustainable genetic-based conservation guidelines of the species in various regions, e.g. in British Islands, Norway, Portugal, Austria, the Czech Republic and Slovakia, Germany, Hungary, Slovenia and Switzerland (e.g. Weiss et al., 2001; Santos et al., 2006; Sonstebo et al., 2007; McKeown et al., 2010; Jug et al., 2005; Keller et al., 2011; Kohout et al., 2012; Lerceteau-Kohler et al., 2013; Thaulow et al., 2013; Osz et al., 2018). In most cases the available studies indicate substantial affection of non-native hatchery stocking material on natural populations. As a result, significant homogenization of genetic structure in wild populations is observed, making difficulties in interpretation of the present share of haplotypes characteristic for particular evolutionary lineage (e.g., share of Danube vs. Atlantic lineage in Central Europe). Moreover, carried out stocking activities may promote hybridization between populations and distinct evolutionary lineages (e.g., Schenekar et al., 2014; Petereit et al., 2018). The present mixing status of numerous brown trout populations in Europe is very complicated, where most of them have been affected by introgression to some degree (reviewed in Bernas \& Was-Barcz, 2020). Many of examples shows the detrimental impact of stocking by non-native material on fitness and survival rates of wild populations by loss of local adaptations resulted from outbreeding depression in subsequent generations (e.g., Wang et al., 2002; Agren et al., 2019).

The increasing tendency in stocking quotas in tenders for fishery operation rights in Poland, shows considerable obstacles in use of locally produced material. Therefore, the use of geographically and genetically distant stocking material, that frequently characterize by insufficient quality is a common practice. This circumstance points the importance of genetic screening to provide baseline information on genetic condition and characteristics of wild and local populations of brown trout for development of sustainable fishery supplementation programs. The knowledge on genetic condition of stationary populations of brown trout provides information on the effectiveness of currently held stocking programs and clues on the proper selection of source material for this purpose (e.g., Tabatabaei et al., 2020). In Poland, most of carried out studies mainly focuses on anadromous populations and available hatchery, where many stationary freshwater populations have not been investigated yet (e.g., Wenne et al., 2016; Bernas \& WasBarcz, 2020). Although information on the genetic diversity and differentiation are crucial during every 
restitution program such data are still absent for the brown trout populations inhabiting TNP in Poland. The present study will provide the first data for assessment of the effectiveness and improvement of currently held fishery supplementation programs of the brown trout in the TNP. The performed under the current study genetic analysis will enlarge and supplement our knowledge on the genetic status of the brown trout across Europe. Beside crucial importance in development of sustainable protection of the species in TNP, the acquired new genetic data can be useful in the future phylogeographic studies in the context of assessment the species' genetic structure and fitness, past and present distribution dynamics, extent of hybridization and evolutionary history.

For this end, the main objective of the present study was the genetic characteristics of the brown trout from Tatra National Park in Poland by application of the selected microsatellite and mitochondrial DNA markers analysis.

\section{Materials and Methods}

\section{Sampling and DNA Extraction}

In 2012, a total of 14 sampling sites were electrofished across 7 main streams located in TNP and ninety-six ( $n=96)$ specimens phenotypically identified as brown trout were collected (Figure 1). The sample collection was carried out during ichthyofauna inventory of TNP. The sampling locations has been selected on field observation of the species availability in the area. The sample sizes were mainly imposed by species abundance and generally, the sampling collection tended to get the most representative data from separate stream systems within the TNP._Fish were photographed, measured, and weighed, without age assessment. The sex of the fish was confirmed, based on the gonad morphology, analyzed after dissection. Obtained fish tissues (fin clips) were placed in the Eppendorf tubes and kept in $96 \%$ ethanol at a temperature of $4^{\circ} \mathrm{C}$ until DNA extraction. The genomic DNA was extracted using Genoplast Tissue Genomic DNA Extraction Mini Kit (Genoplast, Poland) following the manufacturer's protocol.

\section{Polymerase Chain Reaction Amplification (PCR)}

Ten microsatellite loci: Ssa-85, Ssa-171, Ssa-197, Brun-25, Str-12, Str-15, Str-58, Str-60, Str-73 and Str-543 (Sonstebo et al., 2007, Meraner et al., 2010) were used for genetic screening of the sampled fish. Moreover, one fragment of mitochondrial DNA encoding the D-loop region (CR) (Tosic et al., 2014) was used for molecular verification of species membership and genetic purity of examined individuals. The amplification of the chosen microsatellite and mitochondrial DNA fragments were carried out using primer sets and conditions previously described by Sonstebo et al. (2007), Meraner et al. (2010) and Tosic et al. (2014).

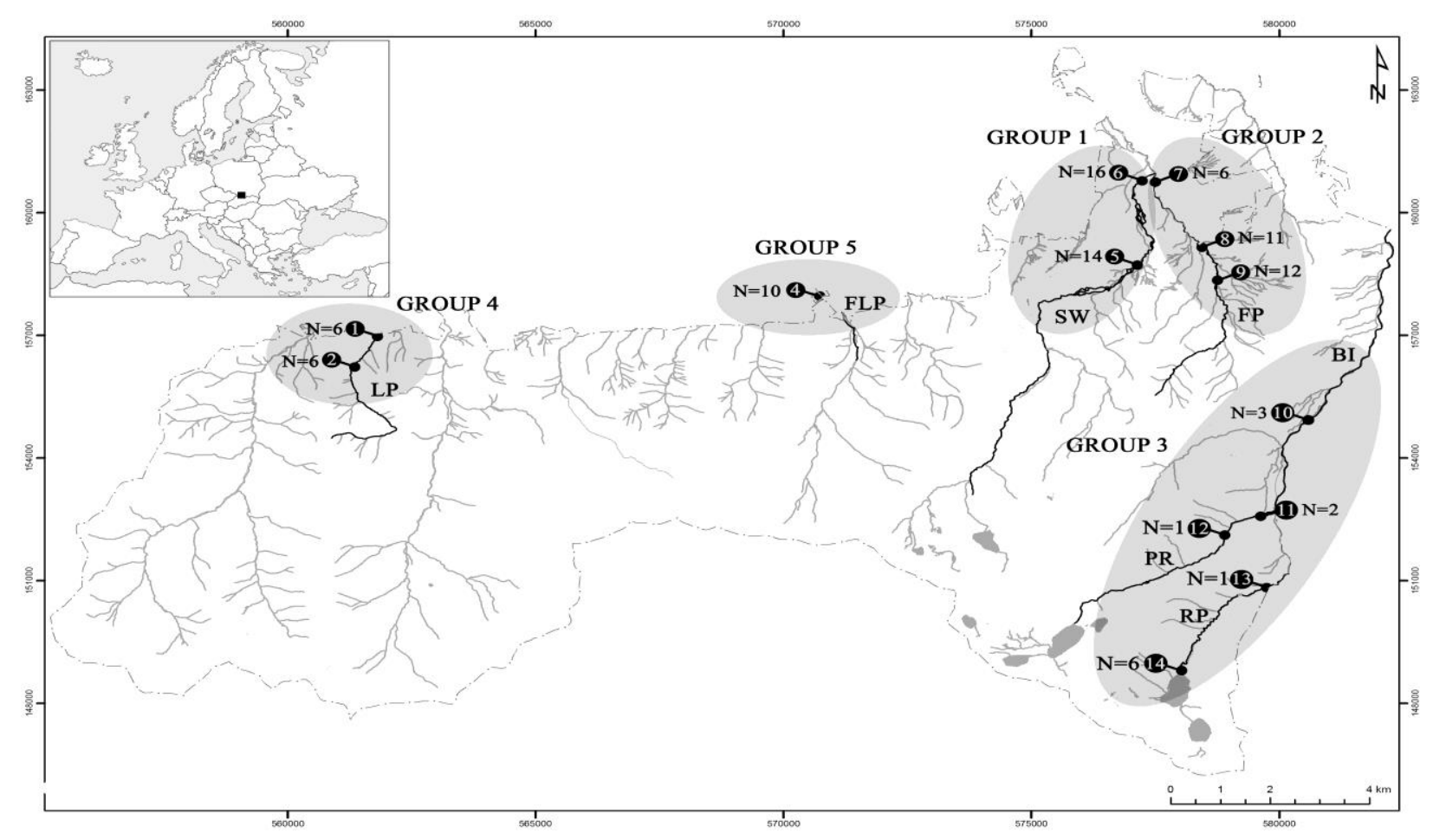

Figure 1. Map of the Tatra National Park (TNP) in Poland, showing all 13 geographical sampling positions across 7 main streams located on territory of the TNP. Abbreviation of streams' names: LP - Lejowy Potok, KP - Kościeliski Potok, FLP - Foluszowy Potok, SW - Sucha Woda, FP - Filipczański Potok, BI - Białka, PR - Potok Roztoka, RP - Rybi Potok. N: sample size. Gray brackets represent fish groups arrangement for data analysis. 


\section{Genotyping and Sequencing}

In order to enable genotyping of amplified microsatellite DNA fragments, 5'-labeled with different fluorescent reporter dyes (PET, VIC, 6-FAM and NED) forward primers were used. The GeneScan 600LIZ size standard was applied as a reference for determining the allele size profiles within each microsatellite loci studied. The genotyping was performed using an Applied Biosystems Genetic Analyser 3130 sequencer (Applied Biosystems, California, USA). The same equipment was also utilized for sequencing the D-loop (CR) mitochondrial DNA region. Shortly, the amplified DNA templates were subjected to purification by DNA ClenUp Kit (A\&A Biotechnology) and subsequently used for sequencing PCR reactions. All sequencing reactions were prepared using BigDye Terminator v3.1 Cycle Sequencing Kit (Applied Biosystems, California, USA) following the manufacturer's protocol with slight modifications. Finally, the amplified, fluorescently labeled and terminated DNA was purified with ExTerminator nucleotide terminators removal kit (A\&A Biotechnology, Poland) and sequenced. To visualize the results of microsatellite DNA analysis, software provided by manufacturer Genemaper v4.1 software and Data Collection Software v3.0 (Applied Biosystems, California, USA) were used. The genetic profiles containing the list of alleles detected within the studied loci were prepared for each fish. For display and save the retrieved sequences of $C R$ mitochondrial DNA fragment, the manufacturer's Sequence Scanner software v1.0 (Applied Biosystems, California, USA) was used.

\section{Data Analysis}

The acquired mtDNA sequences were aligned using the computer program ClustalX (version 2.1) (Larkin et al., 2007). The identified haplotypes of $C R$ were compared to sequences deposited in the NCBI gene bank using BLAST software (NCBI-NIH). Furthermore, haplotype $(h)$ and nucleotide diversity $(\pi)$ as well as an average number of nucleotide differences $(K t)$ were assessed by DNAsp software (version 5.1) (Librado \& Rozas, 2009). For phylogenetic analysis of sampled fish MEGAX software (version 10.1.8) was used (Kumar et al. 2018). Phylogenetic analysis was conducted using Nieghbor-joining (NJ), UPGMA and maximum likelihood (ML) methods. To delineate the historical demography of studied fish based on obtained mtDNA data, the Tajima's D, Fu's Fs statistics as well as the Bayesian skyline plot were carried out by Arlequin (version 3.5) (Excoffier \& Lischer, 2010) and BEAST (version 1.8.2) (Drummond et al., 2012) computer packages.

Before in-depth microsatellite DNA analysis, the retrieved raw data on the individual genetic profiles of each studied fish were entered into Office Excel (Microsoft, USA). Then, the received genotype data were checked for microsatellite null alleles, inconsistent values, scoring errors and large drop-out in samples using Micro-Checker software (version 2.2.3) (Van Oosterhout et al., 2004). The genotype data were checked by the criteria of $95 \%$ confidence interval and 1000 randomizations. For genetic characteristics of brown trout from TNP, a set of data analysis approaches were applied. At first, microsatellite allele frequencies, the observed number of alleles per locus $\left(A_{o}\right)$, number of private alleles $\left(P_{a}\right)$, Shannon's index $(I)$, the polymorphism information content (PIC value), GarzaWilliamson index (M-ratio) and inbreeding coefficient (Fis) for each loci within investigated groups of brown trout specimens were calculated by GenAlEx (version 6.5), PowerMarker (version 3.25) and Fstat (version 2.9.3.2) computer software (Goudet, 2002; Liu \& Muse, 2005; Peakall \& Smouse, 2012). The observed ( $\mathrm{Ho}$ ) and expected heterozygosity $(\mathrm{He})$ as well as the HardyWeinberg equilibrium (HWE) test for each locus were calculated using Arlequin software (version 3.5). To assess of a global HWE, probability tests were carried out by Fisher's and Smouse's multilocus analysis methods implemented in Genepop (version 2.9.3.2) and Popgene (version 1.3.2) (Yeh \& Boylet, 1997; Rousset, 2008) software, respectively. The effective population size ( $\mathrm{Ne}$ ) was also estimated for examined fish groups by NeEstimator computer program (version 2.01) (Do et al., 2013). The linkage disequilibrium method was used for computing $\mathrm{Ne}$, where the lowest allele frequency used was 0.02 and $95 \%$ parametric confidence intervals (95\% $\mathrm{Cl})$ were calculated. Next, the genetic structure and differentiation between the examined individuals of brown trout were tested by application of several statistic tests, namely: the genetic differentiation index (Fst), Nei's genetic distance (Da), the analysis of molecular variance (AMOVA), individual genotype assignment test, the greatest variation among groups $(F c t)$ as well as isolation by-distance effect test were utilized, using the Arlequin (version 3.5), SAMOVA (version 2.0) (Dupanloup et al., 2002) and IBD (version 3.23) (Jensen et al., 2005) softwares. To perform genetic differentiation tests, all analyzed samples were preinitially divided into 5 groups according to locations of their geographic origin, i.e., Group 1: SW $(N=30)$, Group 2: FP ( $N=29)$, Group 3: $B I, P R$ and RP $(N=13)$, Group 4: LP $(\mathrm{N}=12)$ and Group 5: FLP $(\mathrm{N}=10)$ (Figure 1). Additionally, to delineate historical demography of the studied fish group a test for the bottleneck assessment was also conducted using the Bottleneck software (version 1.9) testing departure from mutation drift equilibrium based on heterozygosity excess or deficiency (Piry et al., 1999). This method assumes that in non-bottlenecked broodstock (close to mutation drift equilibrium) the value of expected heterozygosity $(\mathrm{He})$ is equal to $\mathrm{Heq}$ (heterozygosity expected in a mutation-drift equilibrium). The excess of $\mathrm{He}$ over $\mathrm{Heq}$ is the evidence of severe reduction in broodstock effective size that may occur because of a bottleneck event. For this purpose, an Infinite Allele Model (IAM), Stepwise Mutation Model (SMM) and two-phase model of mutation (TPM) were tested for sampled fish group. The one-tailed Wilcoxon 
signed rank test were performed to check an overall mutation-drift equilibrium for all examined microsatellite loci under mutation models applied.

To verify the species membership and hybridization within studies species, all obtained sequences of mitochondrial DNA were compared to sequences deposited in NCBI GenBank database by application of BLAST software. In turns, the obtained microsatellite genotyping data was compared between brown trout specimens and genotype profiles of other identified species within studied area by application of genotype assignment test available in Arlequin software (version 3.5).

\section{Results}

\section{Species Membership and Genetic Purity}

Within sampled group of 96 specimens identified as brown trout (Salmo trutta) seven haplotypes were found under D-loop (CR) mitochondrial DNA analysis. Among studied 95 individuals, five haplotypes identical with haplotypes ATcs2, ATcs3, ATcs4 (Athap4), Da1a and A7 that were previously assigned to Salmo trutta and deposited in NCBI GenBank under accession numbers: AF273087, AF274574, AF274575, AY185568 and HQ848358, respectively were observed. In turn, the last (seventh) identified haplotype of $C R$ was highly similar ( $99 \%$ of identity) to sequences described for the rainbow trout (Oncorhynchus mykiss) and was found in one juvenile individual phenotypically identified as brown trout. Despite the presence of three different salmonid species within the sampled area, i.e., brown trout, brook trout (Salvelinus fontinalis) and rainbow trout, any evidence of introgression or other genetic impurities caused by the phenomenon of interspecific hybridization, were not found within studied fish.

\section{Microsatellite and Mitochondrial DNA Polymorphism}

To evaluate the genetic diversity and structure of the brown trout from the studied area in TNP, 95 individuals genetically confirmed as the brown trout were exclusively included for further genetic analyses. The MicroChecker program found no evidence for microsatellite null alleles, stutter miscalls, scoring errors and allelic dropout within obtained microsatellite DNA input data. The size of the alleles at the individual locus ranged between 88 and 264 base pairs (bp). A total of 115 alleles were identified within sampled fish which were variably distributed in each examined fish group and the total number of private alleles, varied from 4 to 7 (Table 1) The final alignment for all examined specimens of the brown trout included $992 \mathrm{bp}$ of sequenced $C R$ mitochondrial DNA region. Within the five $C R$ haplotypes specified for brown trout, a total of 13 (1.3\%) parsimony informative nucleotide positions were polymorphic. The distribution of the haplotypes found in the studied brown trout specimens were at the following frequencies: 0.52 for ATcs2, 0.42 for ATcs3, 0.02 for ATcs4 (AThap4), 0.02 for Da1a and 0.02 for A7 haplotype. The average base composition for the haplotypes was $\mathrm{T}=31.85 \%, \mathrm{C}=22.83 \%, \mathrm{~A}=31.21 \%$ and $\mathrm{G}=14.11 \%$.

\section{Genetic Diversity}

The genetic variability parameters $\left(A o, H o, H e, P_{a}\right.$, I, PIC, $M$ and Fis) of the studied brown trout specimens are shown in table 1 . The polymorphism information content $(P I C)$ and Shannon's index indicated the value ranges from 0.567 to 0.707 and from 1.196 to 1.549 , respectively. The values of fixation index (Fis) were not statistically significant for each examined locus, and mean values ranged between -0.172 to 0.029 (Table 1 ). The mean values of observed $\left(H_{0}\right)$ and expected heterozygosity $\left(H_{e}\right)$ varied from 0,577 to 0,760 and from 0,609 to 0,723 , respectively. Some statistically significant differences between obtained values of $H_{0}$ and $H_{e}$ were observed from 1 (Groups 1,2 ) to 3 loci (Group 3) (Table1). Both applied H-WE probability global tests did not detect any statistically significant $(\mathrm{P}<0.05)$ global deviations of the examined loci from $\mathrm{H}-\mathrm{WE}$ expectations. The estimated effective population size (Ne) for the examined fish groups of brown trout equaled: Group 1=139 (95\% Cl=60.6-infinite), Group 2=68.3 (95\% Cl=46.7-115.7), Group 3=10.4 (95\% Cl=6.218.8), Group $4=46.7$ ( $95 \% \mathrm{Cl}=3.3$-infinite) and Group $5=2.8(95 \% \mathrm{Cl}=1.4-28.8)$. In the case of mitochondrial DNA sequence data analyzed, the computed haplotype diversity $(h)$ and nucleotide diversity $(\pi)$ values were 0.561 and 0.001 , respectively. The average number of nucleotide differences was at the level $K t=1.042$.

\section{Genetic Structure}

Analysis of the genetic structure of the studied fish group by AMOVA method showed that only $6.23 \%$ of the genetic diversity was distributed among predefined sampling subgroups. Moreover, the assessed pair-wise genetic differentiation between the examined fish groups varied from 0.016 do 0.085 , where the global test of differentiation was at the level Fst $=0.062$, being statistically insignificant $(P<0.001)$. The defined largest Fct value using the SAMOVA program was also statistically non-significant $(F c t=0.152, \quad \mathrm{P}=0.09)$. The Mantel test did not show any statistically significant correlation between the pair-wise values of Fst and sampling site distances among studied brown trout individuals ( $\mathrm{R}=0.08, \mathrm{P}=0.175)$. Constructed phylogenetic trees (NJ, UPGMA and ML) displayed uniform pattern of genetic clustering. The results showed presence of two main genetic clustering: (1) first composing haplotypes 1, 2, 3 and 5 and (2) second comprising haplotype 4 . Obtained data on the haplotype frequency in particular groups did not appear to follow any evident geographical pattern (Figure 2). 
Table 1. Genetic diversity parameters of the studied brown trout individuals under current study. $A_{0}$ : observed number of alleles, $A_{e}$ : number of effective alleles, Ho: observed and He: expected heterozygosity, $\mathrm{P}_{\mathrm{A}}$ : number of private alleles I: Shannon's index, PIC: polymorphism information content, M: Garza-Williamson Index, Fis: fixation index.

\begin{tabular}{|c|c|c|c|c|c|c|c|c|c|}
\hline Group/locus & $\underline{A o}$ & $\underline{\mathrm{Ho}}$ & $\underline{\mathrm{He}}$ & $\underline{P}$ & $\underline{P}_{A}$ & $\underline{I}$ & $\underline{P I C}$ & $\underline{M}$ & $\underline{\underline{F i s}}$ \\
\hline \multicolumn{10}{|c|}{ Group $1 \mathrm{SW}(\mathrm{N}=30)$} \\
\hline Ssa-85 & 4 & 0,484 & 0,465 & 0,910 & & 0,903 & 0,432 & 0,196 & $-0,050$ \\
\hline Ssa-171 & 14 & 0,935 & 0,894 & 0,516 & & 2,384 & 0,884 & 0,140 & $-0,026$ \\
\hline Brun-25 & 15 & 1,000 & 0,888 & 0,726 & 1 & 2,384 & 0,878 & 0,123 & $-0,108$ \\
\hline Ssa-197 & 9 & 0,806 & 0,794 & 0,981 & & 1,790 & 0,766 & 0,128 & $-0,005$ \\
\hline Str-12 & 14 & 0,710 & 0,744 & $0,025^{*}$ & 2 & 1,901 & 0,727 & 0,396 & 0,036 \\
\hline Str-15 & 5 & 0,516 & 0,694 & 0,215 & & 1,308 & 0,639 & 0,333 & 0,314 \\
\hline Str-58 & 8 & 0,806 & 0,815 & 0,743 & & 1,816 & 0,790 & 0,452 & 0,030 \\
\hline Str-60 & 4 & 0,516 & 0,535 & 0,559 & 1 & 0,972 & 0,480 & 0,318 & 0,076 \\
\hline Str-73 & 4 & 0,742 & 0,702 & 0,896 & 1 & 1,263 & 0,643 & 0,125 & $-0,028$ \\
\hline Str-543 & 4 & 0,452 & 0,427 & 0,992 & & 0,773 & 0,377 & 0,352 & $-0,048$ \\
\hline \multicolumn{10}{|c|}{ Group 2 FP $(\mathrm{N}=29)$} \\
\hline Ssa-85 & 4 & 0,700 & 0,662 & 0,803 & & 0,903 & 0,827 & 0,197 & $-0,112$ \\
\hline Ssa-171 & 11 & 0,800 & 0,849 & 0,773 & & 2,384 & 0,833 & 0,177 & 0,058 \\
\hline Brun-25 & 16 & 0,925 & 0,902 & $0,001 * * *$ & 2 & 2,384 & 0,894 & 0,121 & $-0,027$ \\
\hline Ssa-197 & 10 & 0,825 & 0,814 & 0,980 & & 1,790 & 0,792 & 0,096 & $-0,010$ \\
\hline Str-12 & 12 & 0,900 & 0,831 & 0,833 & 3 & 1,901 & 0,812 & 0,428 & $-0,106$ \\
\hline Str-15 & 6 & 0,775 & 0,770 & 0,201 & 1 & 1,308 & 0,730 & 0,333 & $-0,066$ \\
\hline Str-58 & 8 & 0,725 & 0,811 & 0,167 & & 1,816 & 0,787 & 0,463 & 0,021 \\
\hline Str-60 & 3 & 0,475 & 0,487 & 0,612 & & 0,972 & 0,399 & 0,272 & $-0,024$ \\
\hline Str-73 & 3 & 0,600 & 0,628 & 0,179 & & 1,263 & 0,552 & 0,145 & 0,056 \\
\hline Str-543 & 5 & 0,575 & 0,482 & 0,898 & & 0,773 & 0,439 & 0,260 & $-0,160$ \\
\hline Average & 7,8 & 0,730 & 0,723 & 0,605 & 2,0 & 1,549 & 0,707 & 0,249 & $-0,037$ \\
\hline \multicolumn{10}{|c|}{ Group $3 \mathrm{BI}, \mathrm{PR}$ and $\mathrm{RP}(\mathrm{N}=13)$} \\
\hline Ssa-85 & 5 & 0,769 & 0,695 & 0,738 & & 1,358 & 0,651 & 0,129 & $-0,225$ \\
\hline Ssa-171 & 8 & 0,538 & 0,636 & $0,002 * *$ & 1 & 1,462 & 0,615 & 0,079 & $-0,135$ \\
\hline Brun-25 & 9 & 0,692 & 0,805 & 0,078 & 4 & 1,881 & 0,783 & 0,093 & 0,066 \\
\hline Ssa-197 & 7 & 0,615 & 0,592 & 0,911 & & 1,318 & 0,569 & 0,257 & $-0,120$ \\
\hline Str-12 & 7 & 0,308 & 0,633 & $0,003 * *$ & 1 & 1,409 & 0,610 & 0,587 & 0,470 \\
\hline Str-15 & 5 & 0,462 & 0,538 & $0,016 *$ & & 1,099 & 0,509 & 0,361 & 0,225 \\
\hline Str-58 & 6 & 0,462 & 0,651 & 0,344 & 1 & 1,347 & 0,615 & 0,407 & 0,207 \\
\hline Str-60 & 3 & 0,769 & 0,530 & 0,259 & & 0,823 & 0,424 & 0,357 & $-0,417$ \\
\hline Str-73 & 3 & 0,615 & 0,565 & 0,975 & & 0,908 & 0,471 & 0,211 & 0,056 \\
\hline Str-543 & 5 & 0,538 & 0,447 & 0,998 & & 0,946 & 0,426 & 0,155 & $-0,077$ \\
\hline Average & 5,8 & 0,577 & 0,609 & 0,615 & 1,8 & 1,255 & 0,567 & 0,264 & 0,005 \\
\hline \multicolumn{10}{|c|}{ Group 4 LP $(\mathrm{N}=12)$} \\
\hline Ssa-85 & 4 & 0,833 & 0,708 & 0,370 & & 1,286 & 0,652 & 0,118 & $-0,044$ \\
\hline Ssa-171 & 5 & 0,667 & 0,764 & 0,440 & & 1,517 & 0,726 & 0,133 & 0,065 \\
\hline Brun-25 & 9 & 1,000 & 0,875 & 0,612 & 3 & 2,138 & 0,862 & 0,077 & 0,000 \\
\hline Ssa-197 & 5 & 0,833 & 0,764 & 0,285 & & 1,517 & 0,726 & 0,067 & $-0,194$ \\
\hline Str-12 & 6 & 1,000 & 0,750 & 0,878 & & 1,561 & 0,712 & 0,666 & $-0,295$ \\
\hline Str-15 & 4 & 0,667 & 0,625 & 0,587 & & 1,127 & 0,559 & 0,354 & 0,000 \\
\hline Str-58 & 4 & 0,667 & 0,653 & 0,193 & 1 & 1,199 & 0,599 & 0,428 & 0,029 \\
\hline Str-60 & 2 & 0,667 & 0,444 & 0,221 & & 0,637 & 0,346 & 0,400 & $-1,000$ \\
\hline Str-73 & 2 & 0,667 & 0,500 & 0,414 & & 0,693 & 0,375 & 0,083 & $-0,333$ \\
\hline Str-543 & 2 & 0,167 & 0,153 & 0,824 & & 0,287 & 0,141 & 0,219 & 0,050 \\
\hline Average & 4,3 & 0,717 & 0,624 & 0,482 & 2,0 & 1,196 & 0,570 & 0,254 & $-0,172$ \\
\hline \multicolumn{10}{|c|}{ Group 5 FLP $(\mathrm{N}=10)$} \\
\hline Ssa-85 & 4 & 0,400 & 0,720 & 0,081 & & 1,332 & 0,672 & 0,137 & 0,529 \\
\hline Ssa-171 & 5 & 1,000 & 0,760 & 0,491 & 1 & 1,505 & 0,720 & 0,157 & $-0,212$ \\
\hline Brun-25 & 6 & 1,000 & 0,800 & 0,451 & & 1,696 & 0,772 & 0,176 & $-0,143$ \\
\hline Ssa-197 & 4 & 0,800 & 0,700 & 0,396 & 1 & 1,280 & 0,645 & 0,142 & $-0,032$ \\
\hline Str-12 & 5 & 0,800 & 0,740 & 0,338 & & 1,471 & 0,701 & 0,428 & 0,030 \\
\hline Str-15 & 5 & 0,800 & 0,760 & 0,132 & & 1,505 & 0,720 & 0,333 & 0,059 \\
\hline Str-58 & 6 & 1,000 & 0,800 & 0,246 & 1 & 1,696 & 0,772 & 0,333 & $-0,143$ \\
\hline Str-60 & 2 & 0,200 & 0,420 & 0,241 & & 0,611 & 0,332 & 0,400 & 0,600 \\
\hline Str-73 & 3 & 0,800 & 0,560 & 0,528 & & 0,950 & 0,499 & 0,125 & $-0,333$ \\
\hline Str-543 & 5 & 0,800 & 0,680 & 0,299 & 3 & 1,359 & 0,642 & 0,217 & $-0,067$ \\
\hline Average & 4,5 & 0,760 & 0,694 & 0,320 & 1,5 & 1,341 & 0,648 & 0,245 & 0,029 \\
\hline
\end{tabular}




\section{Historical Demography}

The applied bottleneck test enabled to assess the potential effects of a genetic bottleneck on the genetic variation within the brown trout sampled. Within the studied fish groups, the tendencies towards He over Heq were detected in most of the loci analyzed. However, statistically significant He>Heq differences were observed only under an Infinite Allele (IAM) model where four loci: Ssa-171, Ssa-197 Ssa-73 and Brun-25 exhibited significant heterozygosity excess. Similarly, the Wilcoxon sign test detected significant $(P<0.05)$ overall heterozygosity excess only under IAM mutation model. All obtained values of M-ratio were lower than $0,68(M<, 068)$, being at the level of 0,245-0,264 (table 1). The Tajima's $D$ indicator displayed statistically significant negative value $(D=-1.599, P=0.022)$. In turn, the received value of $\mathrm{Fu}^{\prime} \mathrm{s} F \mathrm{~F}$ was positive and statistically insignificant ( $F s=0.510, \quad P=0.642)$. Constructed Bayesian skyline plot revealed stable population size, however an evidence of a historical decline of the population size in the studied fish was detected (Figure 3).

\section{Discussion}

It is considered that genetic diversity is associated with the population's fitness, which is commonly defined as the ability to survival and adaptation to changing conditions of the environment (Frankham et al., 2010). Therefore, assessment of the genetic diversity may be a powerful tool to identify the vulnerability of the populations for inbreeding, demographic stochasticity and reduced viability (Frankham et al., 2010). It should be also highlighted that, the numerous genetic studies demonstrated the advantage of geneticbased conservation management during the protection efforts of endangered fish species, enabling proper identification and selection of source of the stocking material that is characterized by the optimal level of genetic diversity (Brzuzan et. al., 2002; Kucinski et al., 2015; Fopp-Bayat et al., 2015). On the other hand, the introgression among native and non-local fish can cause the disturbances in local adaptations by destabilizing the optimal genetic composition, called outbreeding depression (e.g., Weiss et al., 2001; Jug et al., 2005; Santos et al., 2006).

Comparative analysis of $C R$ mitochondrial DNA data clearly evidenced coexistence of the brown trout and the rainbow trout in the streams within the TNP area. The presence of rainbow trout is quite surprising as previously apart from the brown trout, brook trout was the only other salmonid fish species reported in streams from the TNP area (Glowacinski et al., 2011). Presumably, rainbow trout was introduced accidentally to the TNP streams during the brown trout supplementation programs. This assumption is supported by fact that majority of the fish farms producing brown trout stocking material in Poland breed also rainbow trout. Microsatellite DNA analysis of the studied fish group did not reveal any evidence of the interspecies hybridization between brown trout, brook trout and rainbow trout. In fact, hybrids of the brown trout and the rainbow trout show very limited viability, most of such individuals die before hatching (Michalik et al., 2015). On the other hand, brown trout and brook trout hybrids survive efficiently and cohabitation of these two species in TNP potentially may result in the reproductive interactions which can be equally detrimental for both species (Spens et al., 2007; Blanchet et al., 2007; Cucherousset et al., 2008).

Recent genetic study on wild and hatchery broodstocks of brown trout across Poland identified four main genetic clusters. Three of them were distinguished in the northern part of Poland, while the last cluster comprises hatchery stocks from the Carpathian Mountains. The Carpathian cluster was characterized by the highest level of genetic diversity and number of private alleles that clearly differentiate it from remaining clusters. However, the examined fish from the mentioned region exclusively originated from hatcheries located in Slovryb (Slovakia), Myślenice and Folusz (Poland) (Bernas and Was-Barcz 2020). Lack of the genetic clustering within the brown trout from TNP implies that studied individuals of brown trout form a genetically unified assemblage that may share the common gene pool originated from some Carpathian hatchery. In contrast, significant genetic clustering has been described in numerous brown trout populations in Europe where high correlation between genetic differentiation and waterway distance was observed (Razpet et al., 2007; Meraner et al., 2007; Snoj et al., 2009). Absence of the genetic clustering within brown trout individuals from TNP may be caused by the influence of strong stocking activities that might have resulted in the genetic homogenization. On the other hand, an absence of migration obstacles and small area of TNP could also explain this phenomenon.

Similarly, to microsatellite data, obtained results on mtDNA analysis showed weak genetic clustering, where two genetic groupings were identified, however, haplotype frequencies did not follow and geographical pattern (Figure 2). According to the present result, most of identified mtDNA haplotypes (ATcs2, ATcs3, ATcs4/Athap4, Da1a and A7) within the examined fish group were specific for the Atlantic lineage of the brown trout (Cortey \& Garcia-Marin 2002; Snoj et al., 2011). Actually, the Atlantic lineage is widely distributed throughout Europe via natural colonization, as the upper part of the Danube River basin is largely a habitat of the Atlantic lineage, and extensive stocking events (Weiss et al., 2000, 2001; Kohout et al., 2012; LerceteauKohler et al., 2013). To date, introgression between the non-indigenous brown trout and the native trout populations reported across Europe is considered as a major danger, which can lead to a total diminution of the genetic variability in the wild populations (Kohout et al., 2012; Bernas \& Was-Barcz, 2020). Three of five $C R$ 


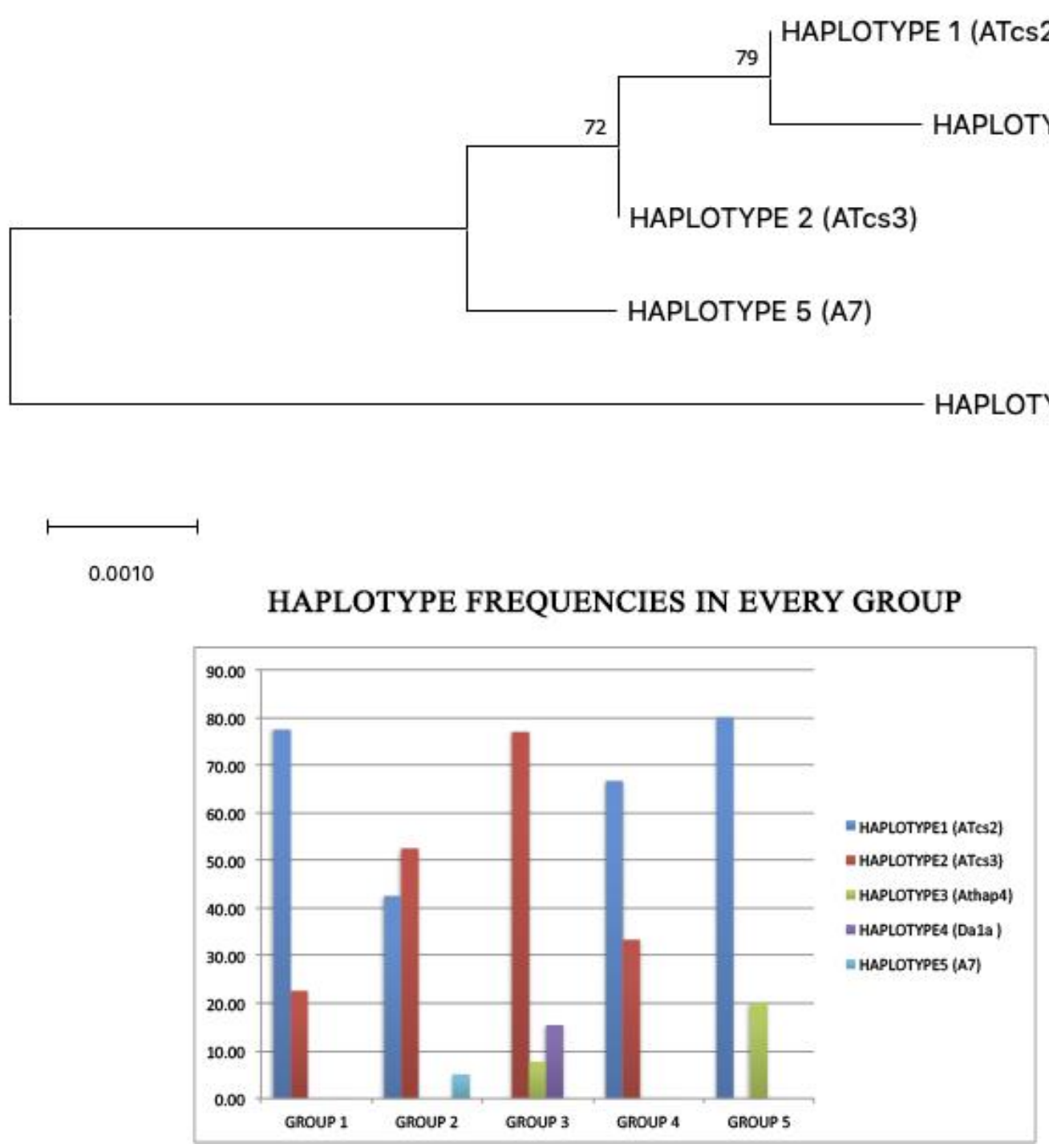

Figure 2. Phylogenetic reconstruction of analyzed CR mitochondrial DNA fragment: based on Neighbor-joining (NJ) method with data on specific haplotype frequencies in every group tested. In parentheses were placed names of identifies haplotypes according to available literature information.

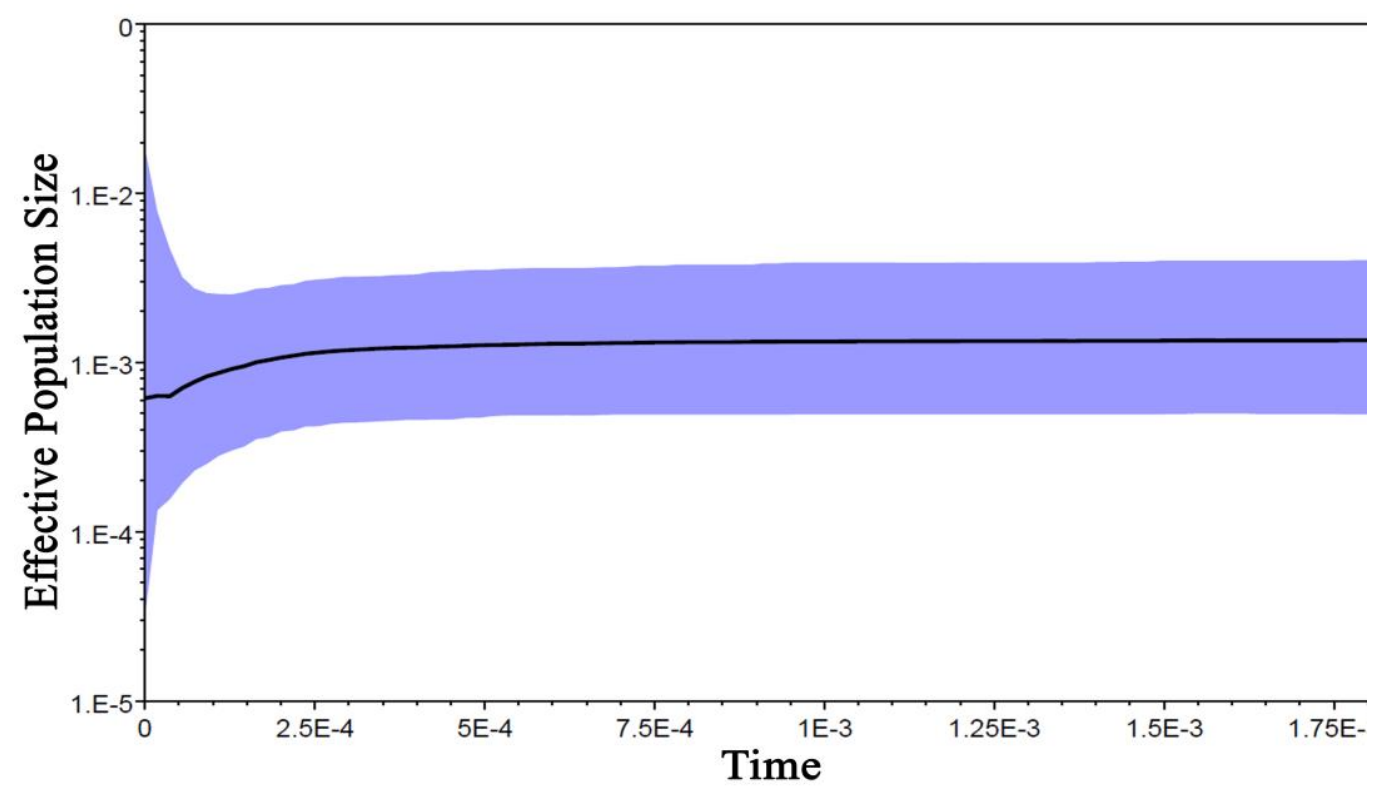

Figure 3. A Bayesian skyline plot from obtained mitochondrial CR sequences for examined fish group under the current study. 
haplotypes (ATcs2, ATcs3 and ATcs4/Athap4) observed among brown trout from the present research were characteristic for the most widespread European hatchery-derived brown trout, including the Carpathian hatcheries (Kohout et al., 2012). On the other hand, the remaining two haplotypes (Da1a and $\mathrm{A} 7$ ) were reported in the wild populations of brown trout across Europe. Da1a haplotype is the one of the widest distributed Danube lineage haplotypes which is deemed as a native in Europe (Meraner et al., 2007; Duftner et al., 2003). This haplotype was previously reported in populations from the upper Vistula River basin, being hypothesized as a sign of post-glacial contacts among populations from the Danube and Vistula basins resulted from recolonization from close but separate refugia deglaciated at different times (Kohout et al., 2012; Bernas et al., 2016). In turn, A7 is the Atlantic lineage haplotype, being found at low frequencies in single brown trout wild populations across Elbe, Oder, Vistula, and Danube River basins (Kohout et al., 2012). A very high frequency (reaching 96\%) of the hatchery strain haplotypes within studied fish may indicate that massive restocking actions caused almost complete extirpation of the native populations of the brown trout in the TNP (Cortey et al., 2009; Snoj et al., 2011; Kohout et al., 2012). The present results suggest that stocking supplementation, carried out in TNP unified genetic pool of studied group of fish. Moreover, the haplotypes Da1a and A7 characterised by low frequencies, may be remnants of the original gene pool of in the studied area. Mentioned haplotypes were identified within Group 2 and 3, which also displayed one and three loci deviated from $\mathrm{H}-\mathrm{WE}$, what may support this assumption (Figure 1, 2).

Examined brown trout were characterized by a moderate level of the genetic diversity $(I=1.196-1.549)$ and $P I C=0.567-0.707$ ) (Table 1). In turn, the overall haplotype $(h)$ and nucleotide diversity $(\pi)$ indices displayed relatively low values, which may suggest that fish material used for the restocking of the TNP originated from the one hatchery source. Similarly, observed statistically insignificant values of the global test of differentiation ( $F s t=0.062, F c t=0.152 \mathrm{P}<0.001$ ) and low value of the genetic diversity distribution among examined fish groups (AMOVA $=6.23 \%$ ) supports the assumption of significant gene pool homogenization of fish in the studied area. According to the available data the Folusz hatchery seems to be the most probable source of stocking material as the hatchery is located most closely to the TNP in terms of reported genetic diversity parameters, however, the exact identification is difficult as the Folusz stock was not analyzed with application of mtDNA (Bernas and Was-Barcz 2020). The observed statistically significant deviations from $\mathrm{H}-\mathrm{WE}$ within Group 2 and 3 may indicate discrete clustering of native genotypes from stocked pool (Table 1). Estimated values of the effective population size within all studied groups were below 100 ( $\mathrm{Ne}<100)$, with exception of Group 1 where $\mathrm{Ne}=139$ was relatively high. According to the obtained results on LD and $N e$, most of examined groups of the brown trout form TNP seems to be susceptible to the genetic drift effect, where only Group 1 seems to be resistant to the genetic drift effect (Frankham et al., 2010). However, recent genetic study on the wild populations of the sea trout (Salmo trutta m. trutta) from the Słupia River (Northern Poland) displayed much highest values of the effective population size ( $\mathrm{Ne}=288$ ) (Bernas et al., 2014).

The bottleneck test applied in the current study showed some evidence of the overall bottlenecks under the IAM mutation model applied. Similarly, received value of Tajima's $D$ and M-ratio indicators seems to support this result indicating significant selection and/or a sudden expansion in population size of examined brown trout from TNP. Most likely, the population/populations of brown trout form TNP underwent a historical bottleneck due to the carried-out fishery supplementation programs. Additionally, massive stocking activities could contribute to genotypes that were selected under hatchery conditions. Nevertheless, the positive value Fu's Fs may indicate the influence of a demographic effects other than a simple sudden expansion, such as rapid population size decrease, partial admixture, or founder effect on the population structure of the fish studied (Marjoram \& Donnelly, 1994). The historical demography assessment based on the Bayesian skyline plot indicated trend of expansion on the effective population size in the examined fish group after a significant decline in the past, supporting that examined fish group could experience the bottleneck effect (Figure 3).

In conclusion, obtained genetic data evidenced that the genetic homogenization and nearly complete extirpation of the native population(s) of brown trout within the studied region had been strongly influenced by the stocking activities performed with the non-native stocking material. Moreover, the held activities of fishery supplementation in the TNP are responsible for introducing alien rainbow trout that can hybridize with brown trout. From the conservation point of view, current study enabled to assess impact of the stocking programs on the wild populations of the brown trout in the TNP and provided baseline data to improve protection programs concerning management of the brown trout in this biologically unique region of Europe. In general, it can propose three main protective measures within the region: (1) assignment the TNP as separate management unit (MU), belonging to the southern genetic lineage according to recent genetic data on brown trout in Poland, (2) application the principle of stocking with local genetic lines, using for the production of stocking material the fish caught in the wild or other the most similar genetic material, (3) implementation the routine verification of the genetic quality and species membership of the stocking material used for fishery supplementation of the TNP waters. However, further wide-scale genetic studies are 
required for the development of sustainable conservation management plans for the ichthyofauna in the studied region.

\section{Ethical Statement}

For this type of study formal consent is not required because the present study characterize by very low level of invasiveness for studied animals. This article does not contain any studies with human participants performed by any of the authors. The Authors fully comply with the ethical principles and standards delineated by the publisher.

\section{Funding Information}

The present research has been conducted under the project entitled: "Ichthyofauna from the streams in the Tatra National Park (TNP), Poland" commissioned and financed by Tatra National Park and the Forest Fund of National Forests in Poland, respectively. This research was also supported by (UWM) University of Warmia and Mazury project number: 11.610.002-300.

\section{Author Contribution}

Marcin Kuciński, Konrad Ocalewicz, Dorota FoppBayat and Jacek Kozłowski conceived the study. Marcin Kuciński performed the molecular study and data analysis. Marcin Kuciński, Konrad Ocalewicz and Dorota Fopp-Bayat wrote and reviewed the manuscript. Piotr Dynowski and Krzysztof Kozłowski collected the samples and took part in the results interpretation. Dorota FoppBayat and Konrad Ocalewicz supervised the study. All authors approved the manuscript.

\section{Conflict of Interest}

The authors declare that they have no known competing financial interests or personal relationships that could have appeared to influence the work reported in this paper.

\section{Acknowledgements}

We would like to cordially thank the anonymous reviewers for time spent and a lot of valuable advises provided that helped in improvement of the present manuscript.

\section{References}

Agren, A., Vainikka, A., Janhunen, M., Hyvärinen, P., Piironen, J. \& Kortet, R. (2019). Experimental crossbreeding reveals strain-specific variation in mortality, growth and personality in the brown trout (Salmo trutta). Scientific Reports, 9(1), 1-11. https://doi.org/10.1038/s41598018-35794-6

Bardakci, F. Degerli, N. Ozdemir, O. \& Basibuyuk, H.H. (2006). Phylogeography of the Turkish brown trout Salmo trutta
L.: mitochondrial DNA PCR-RFLP variation. Journal of Fish Biology, 68, 36-55. https://doi.org/10.1111/j.00221112.2006.00948.x

Bernas, R. \& Was-Barcz, A. (2020). Genetic structure of important resident brown trout breeding lines in Poland. Journal of Applied Genetics, 61, 239-247. https://doi.org/10.1007/s13353-020-00548-6

Bernas, R., Burzynski, A., Debowski, P., Pocwierz-Kotus, A. \& Wenne, R. (2014). Genetic diversity within sea trout population from an intensively stocked southern Baltic river, based on microsatellite DNA analysis. Fisheries Management and Ecology, 21, 398-409. https://doi.org/10.1111/fme.12090

Bernaś, R., Poćwierz-Kotus, A., Dębowski, P. \& Wenne, R. (2016). The genetic relationship between extirpated and contemporary Atlantic salmon Salmo salar L. lines from the southern Baltic Sea. Genetics Selection Evolution, 48(1), 1-5. https://doi.org/10.1186/s12711-016-0208-y

Bernatchez, L. (2001). The evolutionary history of brown trout (Salmo trutta L.) inferred from phylogeographic nested clade, and mismatch analyses of mitochondrial DNA variation. Evolution, 55, 351-379.

https://doi.org/10.1554/00143820(2001)055[0351:TEH OBT]2.0.CO;2

Blanchet, S., Loot, G., Grenouillet, G. \& Brosse, S. (2007). Competitive interactions between native and exotic salmonids: a combined field and laboratory demonstration. Ecology of Freshwater Fish, 16, 133-143. https://doi.org/10.1111/j.1600-0633.2006.00205.x

Brzuzan, P., Kozlowski, J. \& Fopp-Bayat D. (2002). Genetic structure of Polish populations of vendace (Coregonus albula L.) inferred from mitochondrial DNA. Advances in Limnology, 57, 1-10.

Cortey, M. \& Garcia-Marin, J.L. (2002). Evidence for phylogeographically informative sequence variation in the mitochondrial control region of Atlantic brown trout. Journal of Fish Biology, 60, 1058-1063. https://doi.org/10.1111/j.1095-8649.2002.tb02429.x

Cortey, M., Pla, C. \& Garcia-Marin, J.L. (2004). Historical biogeography of Mediterranean trout. Molecular Phylogenetics and Evolution, 33, 831-844. https://doi.org/10.1016/j.ympev.2004.08.012

Cucherousset, J., Aymes, J.C., Poulet, N., Santoul, F. \& Cereghino, R. (2008). Do native brown trout and nonnative brook trout interact reproductively? Naturwissenschafter, 95, 647-654.

https://doi.org/10.1007/s00114-008-0370-3

Dębowski, P. (2018). The largest Baltic population of sea trout (Salmo trutta L.): its decline, restoration attempts, and current status. Fisheries and Aquatic Life, 26(2), 81-100. https://doi.org/10.2478/aopf-2018-0010

Do, C., Waples, R.S., Peel, D., Macbeth, G.M., Tillet, B.J. \& Ovenden, J.R. (2013). NeEstimator V2: reimplementation of software for the estimation of contemporary effective population size $(\mathrm{Ne})$ from genetic data. Molecular Ecology Resources, 14(1), 209 214. https://doi.org/10.1111/1755-0998.12157

Drummond, A.J., Suchard, M.A., Xie, D. \& Rambaut, A. (2012). Bayesian phylogenetics with BEAUti and the BEAST 1.7. Molecular Biology and Evolution, 29, 1969-1973. https://doi.org/10.1093/molbev/mss075

Duftner, N., Weiss, S., Medgyesy, N. \& Sturmbauer, C. (2003). Enhanced phylogeographic information about Austrian brown trout populations derived from complete mitochondrial control region sequences. Journal of Fish Biology, 62, 427-435. https://doi.org/10.1046/j.1095- 
8649.2003.00038.x

Dupanloup, I., Schneider, S. \& Excoffier, L. (2002). A simulated annealing approach to define the genetic structure of populations. Molecular Ecology, 11(12), 2571-2581. https://doi.org/10.1046/j.1365-294X.2002.01650.x

Earl, D.A. \& von Holdt, B.M. (2011). STRUCTURE HARVESTER: a website and program for visualizing STRUCTURE output and implementing the Evanno method. Conservation Genetics Resources, 4, 359-361. https://doi.org/10.1007/s12686-011-9548-7

Evanno, G., Regnaut, S. \& Goudet, J. (2005). Detecting the number of clusters of individuals using the software STRUCTURE: a simulation study. Molecular Ecology, 14, 2611-2620. https://doi.org/10.1111/j.1365-294X.2005.02553.x

Excoffier, L. \& Lischer, L. (2010). Arlequin suite ver 3.5: A new series of programs to perform population genetics analyses under Linux and Windows. Molecular Ecology Resources, 10, 564-567. https://doi.org/10.1111/j.17550998.2010.02847.x

FishBase, (2021). http://www.fishbase.org

Fopp-Bayat, D., Kucinski, M., Liszewski, T., Teodorowicz, T., Łączyńska, B. \& Lebeda, I. 2015. Genetic protocol of Atlantic sturgeon Acipenser oxyrinchus (L.) fry for restocking the Vistula river, Poland. Journal of Survey in Fisheries Sciences, 2(1), 1-10, https://doi.org/10.18331/SFS2015.2.1.1

Frankham, R., Ballou, J.D., David, A. \& Briscoe, D.A. (2010). Introduction to Conservation Genetics; 2nd ed. Cambridge University Press, Cambridge.

Galas, J. \& Tonczyk, G. (2020). Nature of Polish Tatra Lakes. Polish River Basins and Lakes-Part II. Springer, Cham, pp. 413-430. https://doi.org/10.1007/978-3-030-12139-6_19

Glowacinski, Z. \& Makomaska-Juchiewicz M. (1992). Fauna of the Polish Tatra Mountains. Mountain Research and Development, 175-191.

Glowacinski, Z., Okarma, H., Pawlowski, J. \& Solarz, W. (2011). Alien species in the fauna of Poland - I. An overview of the status (In Polish). IOP PAN Press, Krakow.

Goudet, J. (2002). Fstat, a program to estimate and test gene diversities and fixation indices (version 2.9.3.2). http://www2.unil.ch/popgen/softwares/fstat.htm

Hellerman, E.M., Grobler, P.J. \& Jones, J.W. (2007). Application of DNA markers for population genetic analysis. In: Liu Z (ed) Aquaculture genome technologies. Blackwell, New York. Pp. 109-136.

IUCN (2021b). Red list of Threatened Species. http://www.iucnredlist.org

IUCN, (2021a). International Union for Conservation of Nature. http://iucn.org

Jensen, J.L., Bohonak, A.J. \& Kelly, S.T. (2005). Isolation by distance, web service. BMC Genetics, 6, 13, https://doi.org/10.1186/1471-2156-6-13

Jug, T., Berrebi, P., \& Snoj, A. (2005). Distribution of non-native trout in Slovenia and their introgression with native trout populations as observed through microsatellite DNA analysis. Biological Conservation, 123, 381-388. https://doi.org/10.1016/j.biocon.2004.11.022

Keller, I., Taverna, A. \$ Seehausen, O. (2011). Evidence of neutral and adaptive genetic divergence between European trout populations sampled along altitudinal gradients. Molecular Ecology, 20(9), 1888-1904. https://doi.org/10.1111/j.1365-294X.2011.05067.x

Kohout, J., Jaskova, I., Papousek, I., Sediva, A. \& Slechta, V. (2012). Effects of stocking on the genetic structure of brown trout, Salmo trutta, in Central Europe inferred from mitochondrial and nuclear DNA markers. Fisheries Management and Ecology, 19, 252-263. https://doi.org/10.1111/j.1365-2400.2011.00828.x

Kottelat, M. \& Freyhof, J. (2007). Handbook of European freshwater fishes. Publications Kottelat. Publisher: Kottelat, Cornol \& Freyhof, BerlinISBN: ISBN 978-2-83990298-4.

Kucinski, M., Fopp-Bayat, D., Liszewski, T., Svinger, V., Lebeda, I. \& Kolman, R. (2015). Genetic analysis of four European huchen (Hucho hucho Linnaeus, 1758) broodstocks from Poland, Germany, Slovakia and Ukraine: implication for conservation. Journal of Applied Genetics, 56(4), 469480. https://doi.org/10.1007/s13353-015-0274-9

Kumar, S., Stecher, G., Li, M., Knyaz, C. \& Tamura K. (2018). MEGA X: Molecular Evolutionary Genetics Analysis across computing platforms. Molecular Biology and Evolution, 35, 1547-1549. https://doi.org/10.1093/molbev/msy096

Larkin, M.A., Blackshields, G., Brown, N.P., Chenna, R., McGettigan, P.A., McWilliam, H., Valentin, F., Wallaca, I.M., Wilm, A., Lopez, R., Thompson, J.D., Gibson, T.J. \& Higgins, D.G. (2007). ClustalW and ClustalX version 2.0. Bioinformatics 23, 2947-2948. https://doi.org/10.1093/bioinformatics/btm404

Lerceteau-Kohler, E., Schliewen, E., Kopun, U. \& Weiss, S. (2013). Genetic variation in brown trout Salmo trutta across the Danube, Rhine, and Elbe headwaters: a failure of the phylogeographic parading. BMC Evolutionary Biology, 13(1), 176. https://doi.org/10.1186/1471-214813-176

Lerceteau-Kohler, E., Schliewen, U., Kopun, T. \& Weiss, S. (2013). Genetic variation in brown trout Salmo trutta across the Danube, Rhine, and Elbe headwaters: a failure of the phylogeographic paradigm? BMC evolutionary biology, 13(1), 1-18. https://doi.org/10.1186/14712148-13-176

Librado, P. \& Rozas, J. (2009). DnaSP v5: A software for comprehensive analysis of DNA polymorphism data. Bioinformatics 25, 1451-1452. https://doi.org/10.1093/bioinformatics/btp187

Liu, K. \& Muse, S.V. (2005). PowerMarker: Integrated analysis environment for genetic marker data. Bioinformatics, 21(9), 2128-2129. https://doi.org/10.1093/bioinformatics/bti282

Maric, S. Susnik, S. Simonovic, P. \& Snoj, A. (2006). Phylogeographic study of brown trout from Serbia, based on mitochondrial DNA control region analysis. Genetics Selection Evolution, 38, 411-430 https://doi.org/10.1186/1297-9686-38-4-411

Marjoram, P. \& Donnelly, P. (1994). Pairwise comparison of mitochondrial DNA in subdivided populations and implications for early human evolution. Genetics, 136, 673-683.

McKeown, N.J., Hynes, R.A., Duguid, R.A., Ferguson, A. \& Prodohl, P.A. (2010). Phylogeographic structure of brown trout Salmo trutta in Britain and Ireland: glacial refugia, postglacial colonization and origins of sympatric populations. Journal of Fish Biology, 76, 319-347. https://doi.org/10.1111/j.1095-8649.2009.02490.x

Meraner, A., Baric, S., Pelster, B. and Via, J.D. (2007). Trout (Salmo trutta) mitochondrial DNA polymorphism in the centre of the marble trout distribution area. Hydrobiologia, 579, 337-349. https://doi.org/10.1007/s10750-006-0479-3

Meraner, A., Baric, S., Pelster, B. \& Via, J.D. (2010). 
Microsatellite DNA data point extensive but incomplete admixture in a marble and brown trout hybridization zone. Conservation Genetics, 11, 985-998. https://doi.org/10.1007/s10592-009-9942-9

Michalik, O., Dobosz, S., Zalewski, T., Sapota, M. \& Ocalewicz, K. (2015). Induction of gynogenetic and androgenetic haploid and doubled haploid development in the brown trout (Salmo trutta Linnaeus 1758). Reproduction in Domestic Animal, 50, 256-262.

https://doi.org/10.1111/rda.12480

Osz, A., Horvath, A., Hoitsy, G., Sipos, D.K., Keszte, S., Safrany, A.J., Maric, S., Palko, C., Toth, B., Urbanyi, B. \& Kovacs, B. (2018). The genetic status of the Hungarian brown trout populations: exploration of a blind spot on the European map of Salmo trutta studies. PeerJ, 6, p. e5152. https://doi.org/10.7717/peerj.5152

Peakall, R. \& Smouse, P.E. (2012). GenAlEx 6.5: genetic analysis in Excel. Population genetic software for teaching and research-an update. Bioinformatics, 28, 2537-2539. https://doi.org/10.1093/bioinformatics/bts460

Petereit, C. Bekkevold, D. Nickel, S. Dierking, J. Hantke, H. Hahn, A. Reusch, T. \& Puebla, O. (2018). Population genetic structure after 125 years of stocking in sea trout (Salmo trutta L.). Conservation Genetics, 19(5), 11231136. https://doi.org/10.1007/s10592-018-1083-6

Piry, S., Luikard, G. \& Cornuet, J.M. (1999). Bottleneck: A computer program for detecting recent reductions in effective population size from allele frequency data. Journal of Heredity, 4, 502-503.

Razpet, A., Susnik, T., Jug, T. \& Snoj, A. (2007). Genetic variation among trout in the River Neretva basin, Bosnia and Herzegovina. Journal of Fish Biology, 70, 94-110. https://doi.org/10.1111/j.1095-8649.2007.01392.x

Rousset, F. (2008). GenePop'007: a complete reimplementation of the GenePop software for Windows and Linux. Molecular Ecolology Resources, 8(1), 103106. https://doi.org/10.1111/j.1471-8286.2007.01931.x

Santos, N.P., Fontainhas-Fernandes, A.A., Faria, R., TorresCastro, L.F., Anjos, M.R., Cortes, R.M.V. \& Alexandrino, P. (2006). Genetic evidence for limited introgression between wild and stocked individuals in Portuguese brown trout, Salmo trutta populations. Folia Zoologica, 55, 433-443.

Snoj, A., Maric, S., Bajec, S.S., Berrebi, P., Janjani, S. \& Schoffmann, J. (2011). Phylogenetic structure and demographic patterns of brown trout in North-West Africa. Molecular Phylogenetics and Evolution, 61, 203211. https://doi.org/10.1016/j.ympev.2011.05.011

Snoj, A., Maric, S., Berrebi, P., Crivelli, A., Shumka, S. \& Susnik, S. (2009). Genetic architecture of trout from Albania asrevealed by mtDNA control region variation. Genetics Selection Evolution, 41, 22.

https://doi.org/10.1186/1297-9686-41-22

Sonstebo, J.H., Borgstrom, R. \& Heun, M. (2007). Genetic structure of brown trout (Salmo trutta L.) from Hardangervidda mountain plateau (Norway) analyzed by microsatellite DNA: a basis for conservation guidelines. Conservtion Genetics, 8, 33-44. https://doi.org/10.1007/s10592-006-9145-6

Spens, J., Alanara, A. \& Eriksson, L.O. (2007). Non-native brook trout (Salvelinus fontinalis) and the demise of native brown trout (Salmo trutta) in northern boreal lakes: stealthy, long-term patterns? Canadian Journal of Fisheries and Aquatic Sciences, 64, 654-664. https://doi.org/10.1139/f07-040
Suárez, J. Bautista, J.M. Almodóvar, A. \& Machordom, A. (2001). Evolution of the mitochondrial control region in Palaearctic brown trout (Salmo trutta) populations: the biogeographical role of the Iberian Peninsula. Heredity, 87, 198-206. https://doi.org/10.1046/j.1365- 2540.2001.00905.x

Tabatabaei S.N. Abdoli A. Segherloo I.H. Normandeau E., Ahmadzadeh F., Nejat F. \& Bernatchez, L. (2020). Finescale population genetic structure of Endangered Caspian Sea trout, Salmo caspius: implications for conservation. Hydrobiologia, 847(16), 3339-3353. https://doi.org/10.1007/s10750-020-04334-7

Thaulow, J., Borgstrom, R. \& Heun, M. (2013). Brown trout population structure highly affected by multiple stocking and river diversion in a high mountain national park. Conservation Genetics, 14, 145-158.

https://doi.org/10.1007/s10592-012-0438-7

Tosic, A., Skraba, D., Nikolic, V., Mrdak, D. \& Simonovic, P. (2014). New mitochondrial DNA haplotype of brown trout Salmo trutta L. from Crni Timok Drainage Area in Serbia. Turkish Journal of Fisheries and Aquatic Sciences, 14, 37-42. https://doi.org/10.4194/1303-2712-v14_1_05

Turan, D., Kottelat, M. \& Engin, S. (2009). Two new species of trouts, resident and migratory, sympatric in streams of northern Anatolia (Salmoniformes: Salmonidae). Ichthyological Exploration of Freshwaters, 20(8), 333364.

UNESCO, (2021). United Nations Educational, Scientific and Cultural Organization. http://whc.unesco.org

Van Oosterhout, C., Hutchinson, W.F., Wills, D.P.M. \& Shipley, P. (2004). Micro-Checker: software for identifying and correcting genotypes errors in microsatellite data. Molecular Ecology Notes, 4(3), 535-538. https://doi.org/10.1111/j.1471-8286.2004.00684.x

Wang, S., Hard, J.J. \& Utter, F. (2002). Genetic variation and fitness in salmonids. Conservation Genetics, 3, 321-333. https://doi.org/10.1023/A:1019925910992

Weiss, S., Antunes, A., Schlotterer, C. \& Alexandrino, P. (2000). Mitochondrial haplotype diversity among Portuguese brown trout Salmo trutta L. populations: relevance to the post-Pleistocene recolonization of northern Europe. Molecular Ecology 9, 691-698. https://doi.org/10.1046/j.1365-294x.2000.00910.x

Weiss, S., Schlotterer, C., Waidbacher, H. \& Jungwirth, M. (2001). Haplotype (mtDNA) diversity of brown trout Salmo trutta in tributaries of the Austrian Danube: massive introgression of Atlantic basin fish - by man or nature? Molecular Ecology, 10, 1241-1246. https://doi.org/10.1046/j.1365-294X.2001.01261.x

Wenne, R., Bernaś, R., Poćwierz-Kotus, A., Drywa, A. \& Wąs, A. (2016). Recent genetic changes in enhanced populations of sea trout (Salmo trutta $\mathrm{m}$. trutta) in the southern Baltic rivers revealed with SNP analysis. Aquatic Living Resources, 29(1), 103. https://doi.org/10.1051/alr/2016012

Witkowski, A., Popiolek, M., Blachuta, J., Kusznierz, J., \& Kotusz, J. (2008). The brown trout Salmo trutta $m$. fario L. from lake Maly Staw (Giant Mts., SW Poland) - a biological and parasitological survey. Opera Corcontica, 45, 151.

Yeh, F.C. \& Boylet, J.B. (1997). Population genetic analysis of codominant and dominant markers and quantitative traits. Belgian Journal of Botany, 129, 157. 